\title{
Influence of ventilation conditions on the radon annual effective dose of the lungsimulatedfor radon prone areas of Ramsar
}

\author{
Mehdipour L.A ${ }^{1,2^{*}}$, DoostMohammadi $\mathrm{F}^{3}$, Saion $_{\mathrm{EB}^{2}}$, Qasemi $\mathrm{N}^{3}$, Hadavi $\mathrm{M}^{4}$ \\ ${ }^{1}$ PhD in Applied radiation physics, radiology department, faculty of paramedical sciences, Rafsanjan University \\ of Medical Sciences (RUMS), Rafsanjan, Iran. \\ ${ }^{2} P h D$ in Applied radiation physics, physics department, faculty of science, University Putra Malaysia(UPM), \\ Malaysia \\ ${ }^{3}$ Radiology student, radiology department, faculty of paramedical sciences, Rafsanjan University of Medical \\ Sciences (RUMS), Rafsanjan, Iran. \\ ${ }^{4} \mathrm{PhD}$ student in epidemiological sciences and academic staff in paramedical faculty, Rafsanjan University of \\ Medical Sciences (RUMS), Rafsanjan, Iran.
}

\begin{abstract}
Ramsar of northern Iran located on the littoral of the Caspian Sea is considered one of the radon prone areas of the world. The annual effective dose in the district of Talesh-Mahalleh is higher than the dose limits for radiation workers by at least 13 times. In the present study, the indoor radon concentration and radon annual effective dose of the lung were estimated using a Prassi portable radon gas survey meter in a ventilated model house containing top soil samples from different parts of Ramsar. The average wind speed was maintained at $3.0 \mathrm{~ms}^{-1}$ matching the average wind speed of the region. For the extremely hot samples, the annual effective dose of the lung was $111 \pm 10.20 \mathrm{mSv} y^{-1}$ when the windows closed. However, when the windows opened in the wind direction and in the opposite wind direction, the annual effective doses of the lung were $2.46 \pm 0.86$ and $4.16 \pm 0.81 \mathrm{mSvy}^{-1}$, respectively. Also, when the crossed windows opened in no wind condition, the radon annual effective dose of the lung was $5.43 \pm 0.86 \mathrm{mSvy}^{-1}$. The results suggest by opening the windows a significant reduction of the radon annual effective dose in buildings of Ramsar can be achieved.
\end{abstract}

Key words: radon gas, annual effective dose, natural ventilation, Ramsar

\section{Introduction}

Radon is known to present a risk of lung cancer when it, or rather its decay products, is inhaled[1]Exposing to natural radioactive gas of radon is the second main important causes of lung cancer after cigarette smoking [2]. It has been reported that, the radon health risk i.e. the effective dose of lung, is proportional to radon concentration, above to the Environmental Protection Agency's action level of $148 \mathrm{Bqm}^{-3}$, which corresponds to a lung effective dose of $8.80 \mathrm{mSv} \mathrm{y}^{-1}$. The ICRP recommendation annual dose limit for radon is $2.5 \mathrm{mSv} \mathrm{y}^{-1}$ or $6 \mathrm{mSv}$ annual effective doses for the lung. High background radon concentration radiation is primarily because of the presence of very high amounts of ${ }^{226} \mathrm{Ra}$ isotope and its decay products, which are brought to the Earth's surface by hot springs[3]. It is largely accepted that the human activitymodifies the Earth's surface and therefore the radiation exposure may be considered as an ever-changing parameter [4]. A measurement of radon concentration in soil air is a useful tool in the planning and construction of new buildings in order to avoid high indoor radon concentration received by the residents[5]. Latest studies show that radon inhalation even at low levels poses a risk of rising lung cancer[6]. Additionally, there were published reports indicating that the environmental radon exposure may be a risk factor for squamous cell carcinoma or chronic obstructive pulmonary disease (COPD) mortality[7]. About 2,000 inhabitants in the high level natural radiation areas (HLNRAs) of Ramsar, a coastal city in north of Iran were exposed to ionizing radiation of annual absorbed dose of $260 \mathrm{mSv} \mathrm{y}^{-1}$ [3]. Radon gas has 39 isotopes, but Radon-222 (radon) and radon-220 (Thoron) are the most common isotopes of radon. The annual radiation absorbed dose in HLNRAs of Ramsar, in particular in Talesh-Mahalleh district, isabout 13 times higher than the ICRP-recommended radiation dose limits for radiation workers[8]. The high background radiation in the hot areas of Ramsar is primarily due to the presence of very high amounts of ${ }^{226} \mathrm{Ra}$ isotope and its decay products, which are brought to the Earth's surface by hot mineral water fountains[3].Because of local geology, which includes high concentrations of radium in rocks, soils, and water, the people in Ramsar are also exposed to high levels of alpha particles in the form of ingested radium and its decay progenies as well as very high radon levels in their dwellings, over $3000 \mathrm{~Bq} \mathrm{~m}^{-3}$ in some cases[9]. Much the radon largest doses to human organ are in the respiratory tract that is to lung and to theextra-thoracic part of the respiratory tract[10].Theindoor radon level in some regions of Ramsar is higher than the recommendationof W.H.O.The reason for this high indoor radon levels, is the presence of many hot springs, and also local building materials which were used in the buildings. Moreover, the buoyancy effect caused by temperature differences makes a variation in radon concentration due to air flow. The size and 
location of windows in each dwelling determine the extent of natural ventilation, and this important effect could reduce the radon levels and consequently the radon effective dose of thelung is reducedto acceptable levels in HLNRAsof Ramsar. This articlediscusses the effect of natural ventilation on the reduction of radon annual effective dose of the lung in HLNRAs of Ramsar-Iran.

\section{Environmental Monitoring and Soil Sampling}

\section{Materials And Methods}

Prior to soil sampling, environmental monitoring in TaleshMahalleh (a well-known district in HBRAs of Ramsar) was performed using a RDS-110 (RADOS Inc, Finland) multipurpose survey meter. The absorbed dose rates in air were measured at one meter above the ground. The top soilswere sampled in four areas with different dose rates, and were analyzed using gamma spectroscopy system. ${ }^{226} \mathrm{Ra},{ }^{232} \mathrm{Th}$ and ${ }^{40} \mathrm{~K}$ concentrations in each soil sample were measuredandaccording totheir specific activities. The soil samples from different areas were categorized as extremely hot (A), severely hot (B), very hot (C), and hot (D).These samples were placed in a model house one after the other. Radon concentration monitoring was performed using a Prassi portable radon gas survey meter and the radon annual effective dose of lung organ was calculated according to different conditions of natural ventilation. The specific activities of ${ }^{226} \mathrm{Ra},{ }^{232}$ Thand ${ }^{40} \mathrm{Kin}$ each sample were determined using a high purity of germanium (HpGe) gamma-ray spectrometer (Canberra).

\section{Model house}

A model house of $65 \times 65 \times 60 \mathrm{~cm}^{3}$ was designed to simulate the Ramsar dwellings (Figure 1). There were windows on the four sides, each with the dimension of $15 \times 15 \mathrm{~cm}^{2}$. Natural ventilation in this model could be effectively enhanced to reduce energy consumption as well as to reduce radon concentration and radon annual effective dose of lung also consequently decreases the ratio of lung cancers. Wind speed and direction of wind toward the houses, especially the traditional architecture of the northern coastal part of Iran, are taken into account.

\section{Radon level measurements}

The measurement of radon levels in soil air is a useful tool in the planning and constructing of new buildings in order to avoid high indoor radon levels[5].Reviewing the literature show us, usually the radon hazardsis stated in unit ofBqm ${ }^{3}$. However, this value cannot be applied as theabsorbed dose or radon effective dose, so we need to define the radiation exposures to individual or a critical organ such as lung, based on suitable units and quantities. The radon annual absorbed dose of the lung calculated based on UNSCEAR 2000 recommendation using the equation of:

$\mathrm{D}_{\mathrm{Rn}}\left(\mathrm{mSv} \mathrm{y}^{-1}\right)=\mathrm{C}_{\mathrm{Rn}}$.D.H.F.T

Where;

$\mathrm{C}_{\mathrm{Rn}}$ is the measured $\mathrm{Rn}-222$ concentration (in $\mathrm{Bq} / \mathrm{m}^{3}$ )

$\mathrm{F}$ is the Rn-222 equilibrium factor indoors (0.4)

$\mathrm{T}$ is the indoor occupancy time $(80 \%)=7000 \mathrm{~h} / \mathrm{y}$ (yearly)

$\mathrm{H}$ is the indoor occupancy factor $(0.4)$, and

$\mathrm{D}$ is the dose conversion factor $\left(9.0 \times 10^{-6} \mathrm{mSv} / \mathrm{h}\right.$ per Bq$\left./ \mathrm{m}^{3}\right)$

The annual absorbed dose to lung at a radon concentration of $100 \mathrm{~Bq} / \mathrm{m}^{3}$ will be $2.5 \mathrm{mSv}$ during of 7000 hours yearly (an occupancy factor of $80 \%$ ) and according to an equilibrium factor of 0.4 as used in ICRP publications[11]. Having the $D_{R n}$, and using the equation below, the radon annual effective dose of the lung in different condition of natural ventilation was calculated from:

$\mathrm{H}_{\mathrm{E}}\left(\mathrm{mSv} \mathrm{y}^{-1}\right)=\mathrm{D}_{\mathrm{Rn}} \cdot \mathrm{W}_{\mathrm{R}} \cdot \mathrm{W}_{\mathrm{T}}$

Where:

$\mathrm{D}_{\mathrm{Rn}}=$ Annual absorbed dose

$\mathrm{W}_{\mathrm{R}}=$ Radiation weighting factor for alpha particles, or alpha particle quality factor 20

$\mathrm{W}_{\mathrm{T}}=$ Tissue weighting factor for the Lung 0.12

\section{Results And Discussion}

Soil sampling locations recorded by GPS and the dose rate at each location are indicated in table 1.The average annual effective dose to population through natural radiation is equal to $2.4 \mathrm{mSv}^{-1}$. Out of $98 \%$ of radiation doses received to human is from natural sources, and $52 \%$ of this amount is due toradon inhalation ofthoron and radon progenies inside of closed areas such as dwellings and workplaces[12], The background radon concentration in the closed lab was measured prior to measuring the radon levels in model house which had an average value of $19.95 \pm 7.78 \mathrm{~Bq} / \mathrm{m}^{3}$ that corresponds thelung effective dose of $1.19 \pm 0.46 \mathrm{mSv} \mathrm{v}^{-1}$. Based on soil analysis, the most important detectable radionuclide element in the collected soil samples was ${ }^{226} \mathrm{Ra}$ which is the immediate parent of ${ }^{222} \mathrm{Rn}$. For A samples (extremely hot soil samples), the mean $( \pm \mathrm{SD})$ radon 
annual effective dose of the lung inside the model house when the windowswere closed, was $111 \pm 10.20 \mathrm{mSv} \mathrm{y}^{-}$ ${ }^{1}$ (Table 2). When the windows opened in the wind direction or opposite the wind direction, the radon annual effective dose of the lung decreased to $2.46 \pm 0.86$ and $4.16 \pm 0.81 \mathrm{mSvy}^{-1}$, respectively and also, when crossed windows opened but in silent condition (no wind), theradon annual effective dose of the lung was reduced to $5.43 \pm 0.86 \mathrm{mSvy}^{-1}$ (Figure 1). The reason for these value reductions is due to differential pressure between indoor and outdoor air which results to reduce the values at the time of measurement. So when there is a relation between indoor and outdoor air, it can be assumed as the presence of fresher outdoor air inside of dwellings and can be so effective and useful tool to dilute the indoor radon levels and its benefits will be the reduction of indoor radon hazards especially for the radon related critical organ of the lung.

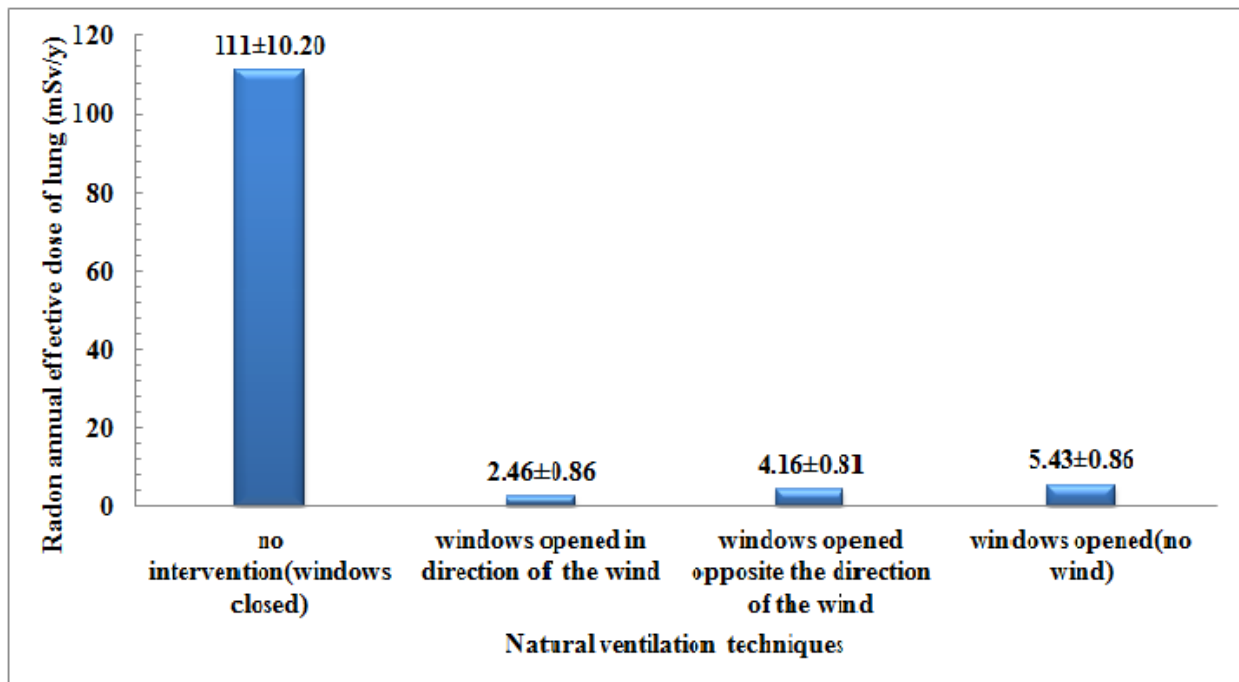

Figure 1Radon annual effective doses of the lung in different condition of natural ventilation techniques (sample A (Extremely hot soil sample))

For B samples (severely hot soil samples), the mean $( \pm \mathrm{SD})$ radon annual effective dose of the lung when the windows were closed, was $10.44 \pm 1.26 \mathrm{mSvy}^{-1}$ (Table 2 ). When the windows were openin the wind direction andopposite of the wind direction, the radon annual effective dose of the lung decreased to $1.92 \pm 0.66$ and $3.39 \pm 0.90 \mathrm{mSv} \mathrm{y}^{-1}$ respectively, and also when crossed windows were opened, but in silent condition(no wind), the radon annual effective dose of the lung was reduced to $2.75 \pm 0.91 \mathrm{mSvy}^{-1}$ (Figure 2).

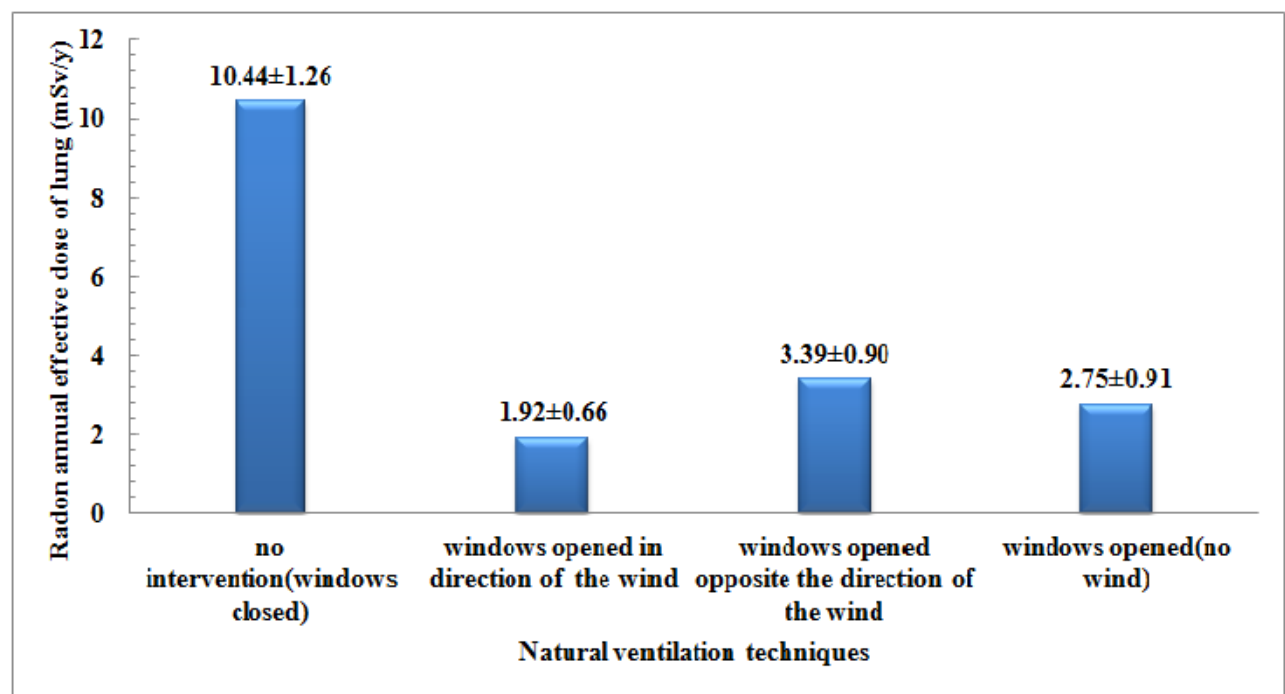

Figure 2Radon annual effective doses of the lung in different condition of natural ventilation techniques (sample B (severely hot soil sample))

Moving to $\mathrm{C}$ samples, the mean $( \pm \mathrm{SD})$ radon annual effective dose of lung when the crossed windows were closed, was $3.27 \pm 0.60 \mathrm{mSv} \mathrm{y}^{-1}$ (Table 2), When cross-windows were opened in the wind direction or opposite the wind direction, the radon annual effective dose of the lung was decreased to $1.74 \pm 0.48$ and 2.28 
$\pm 0.60 \mathrm{mSv} \mathrm{y}^{-1}$, respectively. Also, when crossed windows were opened in a silent condition (no wind), the radon annual effective dose of the lung was $1.88 \pm 0.45 \mathrm{mSv}^{-1}$ (Figure 3).

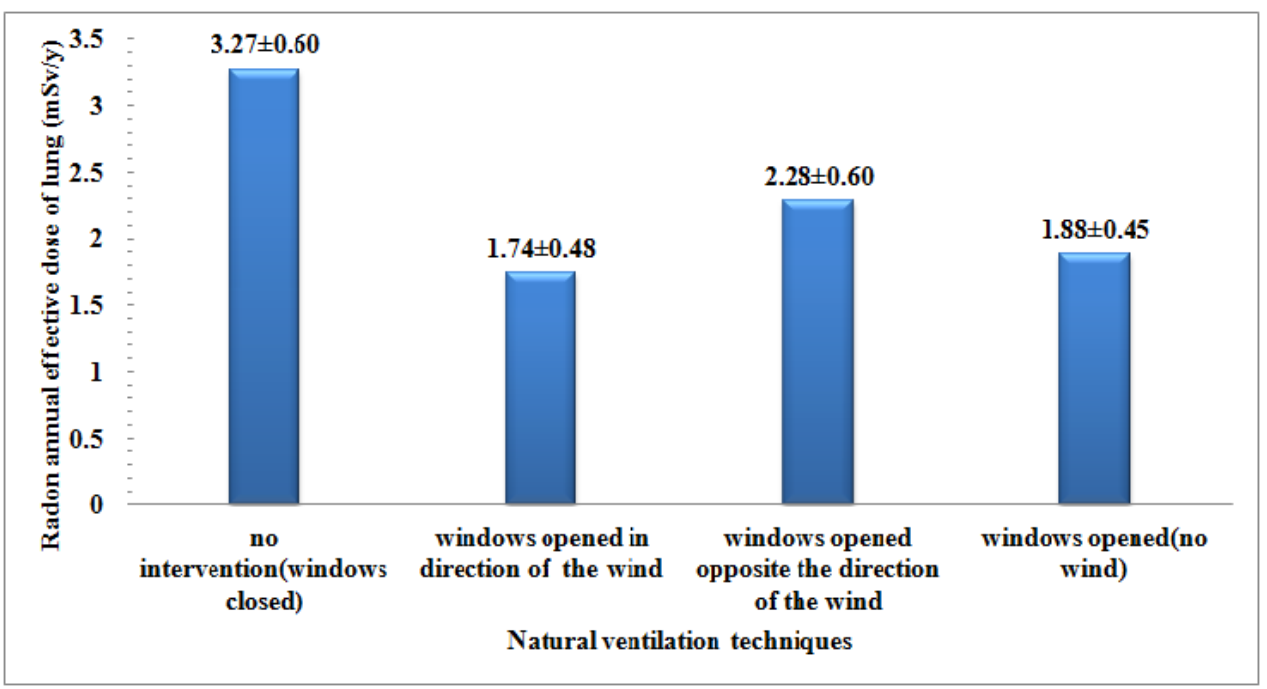

Figure 3Radon annual effective doses of the lung in different condition of natural ventilation techniques (sample C (very hot soil sample))

And finally for $\mathrm{D}$ samples, the mean $( \pm \mathrm{SD})$ radon annual effective dose of lung when all windows were closed, was $2.59 \pm 0.59 \mathrm{mSv} \mathrm{y}^{-1}$ (Table 2). When the windows opened in the wind direction or opposite of the wind direction,the radon annual effective dose of the lung was decreased to $1.68 \pm 0.24$ and $1.98 \pm 0.56 \mathrm{mSv} \mathrm{y}^{-1}$, respectively and in silent condition (no wind) when crossed windows were opened, theradon annual effective dose of the lung was reduced to $1.87 \pm 0.46 \mathrm{mSv}^{-1}$ (Figure 4).

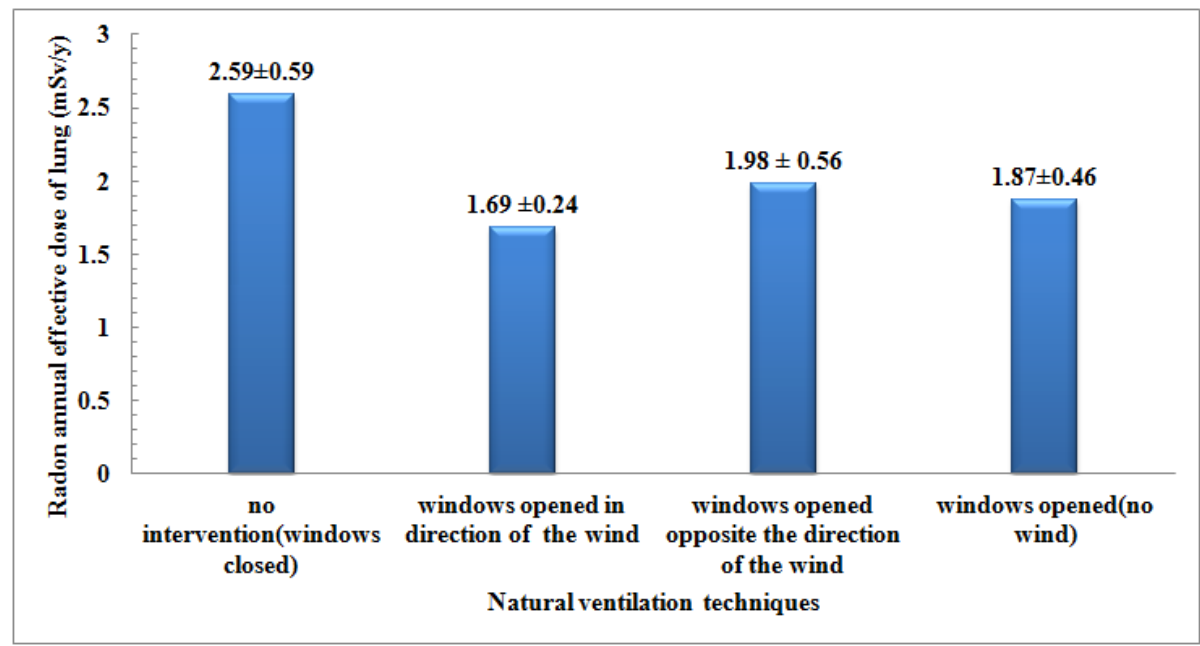

Figure 4Radon annual effective doses of the lung in different condition of natural ventilation techniques (sample D (hot soil sample))

Table 1 Soil sampling locations recorded by GPS and the dose rate at each location

\begin{tabular}{lccccc}
\multicolumn{1}{c}{ Samples } & Latitude & Longitude & $\begin{array}{c}\text { Wind } \\
\text { speed km/h }\end{array}$ & Elevation (m) & $\begin{array}{c}\text { Mean } \pm \text { SD dose } \\
\text { rate }(\mu \text { Sv/hr })\end{array}$ \\
SampleA & N 36.884670 & E 50.683990 & 1 & 17 & $31.82 \pm 4$ \\
SampleB & N 36.885471 & E 50.683529 & 0.2 & 13 & $18.37 \pm 2.9$ \\
SampleC & N 36.885623 & E 50.683594 & 2.7 & 11 & $13.92 \pm 2$ \\
SampleD & N 36.885967 & E50.683662 & 0.1 & 10 & $2.77 \pm 0.9$
\end{tabular}


Influence of ventilation conditions on the radon annual effective dose of the lung simulated for ....

Table 2 Radon annual effective doses of the lung in different condition of natural ventilation techniques

\begin{tabular}{lllll}
\hline Samples & $\begin{array}{l}\text { Windows closed } \\
\text { (No intervention) }\end{array}$ & $\begin{array}{l}\text { Windows opened in the wind } \\
\text { direction }\end{array}$ & $\begin{array}{l}\text { Windows opened opposite } \\
\text { the wind direction }\end{array}$ & $\begin{array}{l}\text { Cross } \\
\text { opened (no wind) }\end{array}$ \\
\hline SampleA & $111 \pm 10.20$ & $2.46 \pm 0.86$ & $4.16 \pm 0.81$ & $5.43 \pm 0.86$ \\
SampleB & $10.44 \pm 1.26$ & $1.92 \pm 0.66$ & $3.39 \pm 0.90$ & $2.75 \pm 0.91$ \\
SampleC & $3.27 \pm 0.60$ & $1.74 \pm 0.48$ & $2.28 \pm 0.60$ & $1.88 \pm 0.45$ \\
SampleD & $2.59 \pm 0.59$ & $1.68 \pm 0.24$ & $1.98 \pm 0.56$ & $1.87 \pm 0.46$ \\
\hline
\end{tabular}

All the findings which are summarized in this table,shown the positive effect of natural ventilation interventions on reduction of radon annual effective dose of the lung for inhabitants of HLNRAs of Ramsar.

Much the largest radon doses are on the respiratory system, which is to the lung and to the extrathoracic part of the respiratory tract [10]. The national cancer institute (NCI) declares, the second leading cause of lung cancer in the United States is radon gas, which is linked with 15,000 to 22,000 lung cancer deaths each year. WHO recommends a national reference level of $100 \mathrm{~Bq} \mathrm{~m}^{-3}$ [1] which is equal to the human absorbeddose of $2.5 \mathrm{mSvy}^{-1}$. WHO also believes that, if this level of radon concentration cannot be reached under the prevailing country-specific conditions, the value should not exceed $300 \mathrm{~Bq} \mathrm{~m}^{-}{ }^{3}$. So according to our results, the natural ventilation effect can act as a simple effective methodof the reduction of lung effective dose.Regarding to W.H.O reports, the main health hazard from high radon exposure is an increased risk of lung cancer[13] and as the effective dose is a factor in determining the cancer risk,according to the findings of this study, it can be concluded that for the extremely hot, severely hot, very hot and hot soil samples, natural ventilation interventions can successfullyreduce the radon effective dose of the lung to lower values. This effect was especially high up inthe extremely hot soil samples. Regarding to our review on meteorological factor of the Ramsar city during the 50 past years, the most common direction of wind during 1955-2005 has been 315 degree. So the direction of openings and establishing the basement of dwellings toward the wind (315degree) will mitigate the radon level and radon effective dose of the lung to lowest values and in result,thus the cancer risk in this region would be reduced to the lowest values possible. One of the most important advantages of this simple technique comparing to other radon mitigation techniques is its low cost, especially for the new buildings and renovated dwellings, becausethe cost of a common radon reduction system in Iran is very expensive for the poor people. Moreover, the people who are living at HLNRAs of Ramsar and its districts on average cannot afford to install the radon reduction systems. So the first more effective methodofconstructinga building in the HLNRAs of Ramsar is designing the basementwindows in regard to meteorological factors.

\section{Conclusion}

Much the largest radon doses are on the respiratory system [14]. Natural ventilation is a primefactor of home freshening in which outdoor air enters the house through openings and the simple cost -effective interventions can significantly reduce the radon concentration[15]. In general,ending of this study shows, thenatural ventilation intervention can not only considerablyreduce the radon concentration in radon prone areas of Ramsar but also its consequences are reduction of radon annual effective dose of lung and finally reduction of lung cancer risks for inhabitants. In this study, the influence of natural ventilation on radon concentration and annual effective dose of lung were set and the authors, recommends strongly using this low cost technique to the inhabitants of Ramsar to reduce unwanted indoor radon radiation hazards.

\section{References}

[1]. Kendal GM, Smith TJ, Doses to organs and tissues from radon and its decay products. Radiat Prot, 2002, 22(4), 389-406.

[2]. WHO. hand book on indoor radon Diagnostic measurements for mitigation and post-mitigation. 2009.

[3]. Ghiassi-nejad M, Mortazavi SMJ, Cameron JR, Niroomand-rad A, Karam PA, Very high background radiation areas of Ramsar, Iran: preliminary biological studies. Health Phys. 2002; 82(1):87-93.

[4]. Sajo-Bohus L, Palfalvi J, Urbani F, Castro D, Greaves ED, Liendo JA. Environmental gamma and radon dosimetry in Venezuela. Radiat measurment, 1999, 31(1-6), 283-286.

[5]. Jönsson, G. Radon gas - where from and what to do? Radiat measu, 1995, 25(1-4), 537-546.

[6]. Barros-Dios JM, Alberto RR, Monica PR. Residential Radon Exposure, Histologic Types, and Lung Cancer Risk. A Case-Control Study in Galicia, Spain. Cancer epid, Bio and prev, 2012; 21(6),951-958.

[7]. Turner MC, Krewski D, Chen Y, Pope CA, Gapstur SM, Thun MJ. Radon and COPD mortality in the American Cancer Society cohort. European Resp,2012, 39(5), 1113-1119.

[8]. Mortazavi S, GhiassiNejad M, Beitollahi M. Very High Background Radiation Areas (VHBRAs) of Ramsar: Do We Need any Regulations to Protect the Inhabitants. Proceedings of the 34th midyear meeting, Radiation Safety and ALARA Considerations for the 21st Century, California, USA 2001:177-82.

[9]. Mortazavi SMJ, Mozdarani H, Roshan-shomal P, Razavi-toosi, Zarghani H, short -term exposure to high levels of natural external gamma radiation does not induce survival adaptive response. IJRR, 2012, 3(10), 165-170.

[10]. Kendal GM, Smith TJ, Doses from radon and its decay products to children. Radiat. Prot, 2005, $25(3), 241$.

[11]. Chen, J. A review of radon doses.Radiat Protec Manag, 2005; 22(4), 27.

[12]. UNSCEAR effects and risks of ionization radiation, sources. 1988, UNSCEAR.

[13]. WHO. Radon and cancer, Fact sheet N²91: World Health Organization (WHO); 2009. 
[14]. Lotf Ali Mehdipour, Elias B Saion, Sidek A.A, Halimah M.K, Mahmoud GoodarzNaseri, AbdolHalimShaari, Manizheh Navaseri1. Influence of chimney effect on the radon effective dose of the lung simulated for radon prone areas of Ramsar in winter season. IOSR-JAP, 2013, 4(4), 33-37.

[15]. L.A. Mehdipour, Dr. S.M.J. Mortazavi, E.B. Saion, H. Mozdarani, S.A. Aziz, H.M. Kamari, R. Faghihi, S. Mehdizadeh, M.R. Kardan, A. Mortazavi. natural ventilation consideration for radon prone areas of Ramsar. International Journal of Radiation Research, 2014, 12(1), 69- 74 